\title{
Increasing rate of Caesarean Section Due to Non-Reassuring Cardiotocography
}

\author{
Pushpa Chetandas, Sana Zahiruddin, Nigar Jabeen, Raheela Baloch, Fouzia Shaikh \\ Obstetrics and Gynecology, Aga Khan University, Karachi, Pakistan \\ Email: pushpasaroop@yahoo.com
}

How to cite this paper: Chetandas, P., Zahiruddin, S., Jabeen, N., Baloch, R. and Shaikh, F. (2017) Increasing rate of Caesarean Section Due to Non-Reassuring Cardiotocography. Open Journal of Obstetrics and Gynecology, 7, 351-357.

https://doi.org/10.4236/ojog.2017.73036

Received: February 10, 2017

Accepted: March 24, 2017

Published: March 27, 2017

Copyright $\odot 2017$ by authors and Scientific Research Publishing Inc. This work is licensed under the Creative Commons Attribution International License (CC BY 4.0).

http://creativecommons.org/licenses/by/4.0/

\begin{abstract}
Objective: To evaluate increasing rate of caesarean section due to non-reassuring cardiotocography. Methods: This study is carried out in obs/gyn department of Liaquat university hospital from 2012 to 2013. After permission from ERC, patients enrolled for study meeting inclusion criteria with nonreactive cardiotocography undergo caesarean section, and results are analysis through SSPS version 17. Results: There was wide variation of maternal age ranging from a minimum of 20 years to 30 years. The mean age was $26 \pm 2.1$ years. In our study mostly patients were primigravida 58 (58\%) between $2-4$ were $22(22 \%)$ more than para 5 were $20(20 \%)$ patients. In our study mostly patients undergone caesarean section 81 (81\%) 19 delivered vaginally (19\%). In our study the gestational age was $>37$ weeks, ranging from a minimum of 37 weeks to 42 weeks. The mean age was $37+2.4$ week. Mostly patients observed 37 - 38 wks in (52.67\%), 39 - 40 wks in (32.14\%) and 41 - 42 wks in (15.17\%). In our study mostly Apgar score were more than 7 was 63 (63\%) cases and less than 7 Apgar score in 37 (37\%). Conclusion: Cardiotocography is a useful and indispensable adjunct to monitor the condition of endangered fetus. However, there is a need to develop a standardized and unambiguous definition of FHR tracing to reduce the incidence of false positive findings that may result in increased incidence of unnecessary intervention particularly caesarean section.
\end{abstract}

\section{Keywords}

Non-Reassuring Cardiotocography, Caesarean Section, Apgar Score

\section{Introduction}

Cardiotocography is the graphic presentation of fetal heart activity and the uterine contraction to detect the fetal hypoxia [1] [2] [3]. It is the most commonly used test for antepartum and intrapartum fetal surveillance in the majority hos- 
pitals of developed countries [4]. This technology was first developed in 1950 and became commercially available in 1960 [1]. The goal of antepartum fetal surveillance is to predict, diagnose and timely decision of the pregnancies those are complicated with fetal asphyxia and might lead to fetal and newborn morbidity and death [5].

IUGR (Intrauterine growth restriction) fetus is at risk of fetal distress and this can be detected by using Cardiotocography. Cardiotocography examination consists of tocogram and ultrasound transducer, tocogram monitor uterine contraction while ultrasound transducer record fetal heart rate [6]. Fetal academia metabolic (95.5\%) mixed (95\%) and respiratory (100\%) can be significantly detected by fetal heart rate monitoring. The pathologic finding of Cardiotocography during labor may increase the caesarean rate [7]. The rate varies between low-income and affluent countries, with global estimates of $15 \%$ worldwide, ranging from a low of $3.5 \%$ in Africa, to $33 \%$ in the United States, to a high of 43.9\% in Brazil [9]. The rate of caesarean section due to fetal distress monitored by cardiotocography from $9.6 \%$ to $19 \%$ as given in different studies [8] [10].

\section{Data Collection Procedure}

This study was carried out in "Department of Gynecology\& Obstetrics" at Liaquat University of Medical \&Health Sciences Hyderabad, from October 2012 to March 2013. This study consisted of 100 patients with gestational age $>37$ weeks, admitted through the outpatient department, as well as from casualty department of University Hospital Hyderabad. All data was entered in a specified proforma designed for this purpose. Detailed Clinical examination of the patient was done. Systemic review was also done to see any co-morbidity. All patients underwent for base line like $\mathrm{CBC}$ and specific investigations especially ultrasound pelvis.

Inclusion criteria were that all patients with gestational age more than 37 weeks with non-reassuring Cardiotocography were included in this study, regardless of their age and parity carrying singleton pregnancy. Exclusion criteria were history of previous caesarean section operation, less than 37 weeks pregnancy, any other obstetrical indication for caesarean section (except non-reactive Cardiotocography), and fetus with congenital anomaly. Data collection procedure. The study was performed after the permission of ethical review committee of Liaquat university Hospital Jamshoro. Patients fulfilling the inclusion criteria admitted in labor ward of Liaquat University Hospital Hyderabad. After taken obstetrical history and obstetrical examination, Cardiotocography were performed as admission test and patient with non-reassuring Cardiotocography were gone for cesarean section and outcome were measured by Apgar score if $>7$ in one minute categorized as good Apgar score and $<7$ in one minute poor Apgar score. After collection of data, the data was analyzed for quantitative variables like age of mother and parity. Frequency and percentages were computed for qualitative variables like Cardiotocography and caesarean section. Effect modifier was concluded through stratification of age and gestational age to see 
the effect of these on outcomes. Through chi square test $\mathrm{p}$ value $<0.05$ will be taken as significance.

\section{Results}

There was wide variation of maternal age ranging from a minimum of 20 years to 30 years. The mean age was $26+2.1$ years (Table 1 ).

In our study mostly patients were primigravidas $58(58 \%)$ between para2 - 4 were $22(22 \%)$ more than para 5 were 20 (20\%) patients (Table 2).

In our study mostly patients undergone caesarean section 81 (81\%) 19 delivered vaginally (19\%) (Figure 1).

In our study the gestational age was $>37$ weeks, ranging from a minimum of 37 weeks to 42 weeks. The mean age was $37+2.4$ weeks (Figure 2 ). Mostly patients observed $37-38 \mathrm{wks}$ in (52.67\%), 39 - $40 \mathrm{wks}$ in (32.14\%) and $41-42 \mathrm{wks}$ in $(15.17 \%)$.

In our study mostly Apgar score were more than 7 was 63 (63\%) cases and less than 7 Apgar score in 37 (37\%) (Figure 3).

Table 1. Maternal age distribution.

\begin{tabular}{ccc}
\hline Age of patients years & No. of patients $(\mathbf{n}=112)$ & Percentage $(\%)$ \\
\hline $20-25$ years & 42 & $42.85 \%$ \\
$26-30$ years & 58 & $57.14 \%$ \\
\hline
\end{tabular}

Table 2. Parity of patients.

\begin{tabular}{ccc}
\hline Parity & No. of patients $(\mathbf{n}=112)$ & Percentage (\%) \\
\hline Primigravida & 58 & $58 \%$ \\
P1 - P4 & 22 & $22 \%$ \\
>P5 & 20 & $20 \%$ \\
\hline
\end{tabular}

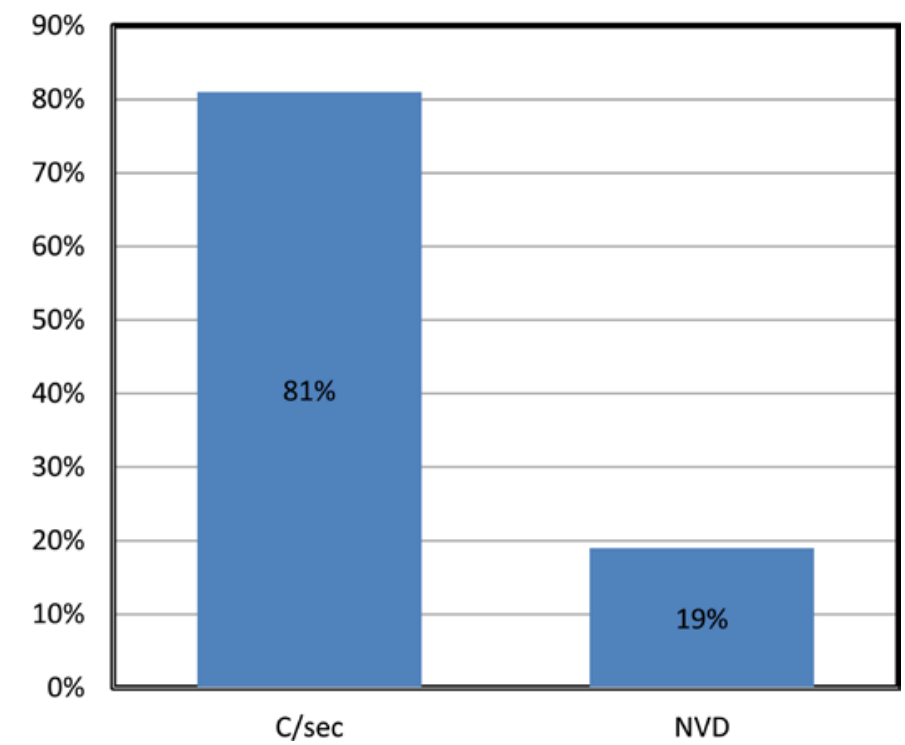

Figure 1. Mode of Delivery. 


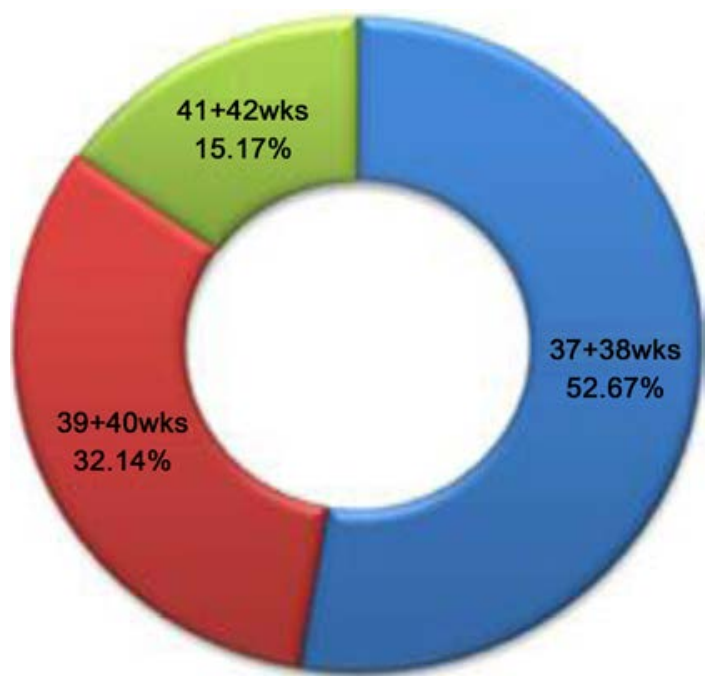

Figure 2. Gestational age distribution.

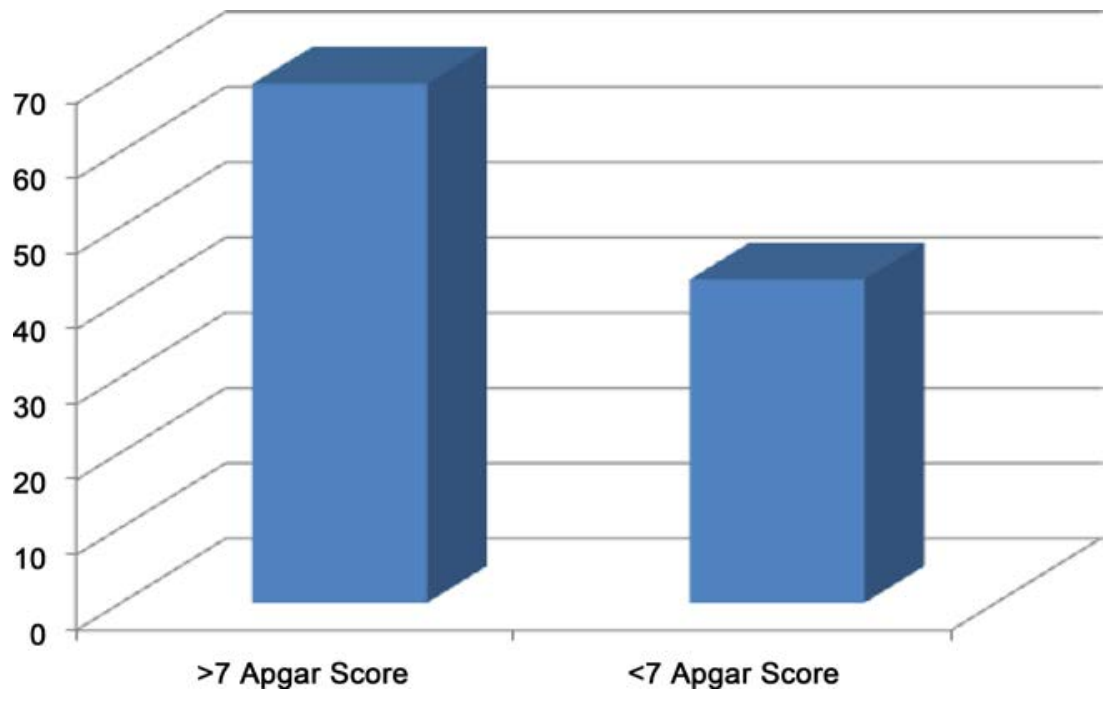

Figure 3. Apgar score.

\section{Discussion}

The Cardiotocography was introduced as a means of attempting to identify those fetuses at greatest risk of intrapartum hypoxia, which might benefit from more intensive monitoring by continuous electronic fetal monitoring and/or fetal scalp blood gas analysis or from immediate intervention e.g. expedited birth.

Cardiotocography as a predictor of fetal distress in low and high risk pregnancies. It is true fact that for management of "high risk woman" there are many available methods but to detect "fetal distress" in "low risk woman" more efficient method required [11]. Many clinics still use Cardiotocography for intrapartum assessment and the management of labor, despite its shortcomings. We combine Cardiotocography with the amniotic fluid index (AFI). The reported 1 -week perinatal mortality rate following a reactive Cardiotocography is 3-5/1000 [11]. Fetal outcome can be better with reactive Cardiotocography but not necessary with nonreactive Cardiotocography. Normal labor is associated 
with abnormalities of fetal heart rate but it is not necessary that fetus is compromised.

In our study, there was wide variation of maternal age ranging from a minimum of 20 years to 30 years. The mean age was $26+2.1$ years. However the study of Birgitta Essen reported the maternal age was maximum number of patients $96 \%$ of them were between 19 and 40 years old [12].

In our study mostly patients were belongs to poor class in $82(73.21 \%)$ cases followed by middle class in 21 (18.75\%) cases and upper class in 7 (6.25\%).In our study mostly patients were uneducated in 84 (75\%) cases and educated in 28 (25\%).

Reliability of cardiotocography is usually at or after 28 weeks. The exact age for commencing cardiotocography is different in different countries because it depends upon availability of neonatal survival facilities [13]. In our study the gestational age was $>37$ weeks, ranging from a minimum of 37 weeks to 42 weeks. The mean age was $37+2.4$ weeks. Mostly patients observed $37-38$ wks in 59 (52.67\%), 39 - 40 wks in 36 (32.14\%) and 41 - 42 wks in 17 (15.17\%).

The wide spread application of cardiotocography has resulted in an increase in the number of obstetric interventions, particularly the incidence of Cesarean Section. The fact that, delivery by Cesarean Section is usual when cardiotocography becomes abnormal was pattern. Observation was made by Oladrian et al. in a study which showed $72 \%$ Cesarean Section rate [14]. A study by Kulkarni and Shroti also showed a progressive rise in operative deliveries for fetal distress from $5.17 \%$ in the reactive group to $28.5 \%$ in the ominous group [15]. Other studies also established the association between a high Cesarean Section rate and an abnormal cardiotocography [16] [17]. It was noticed that rate of Cesarean Section increased when cardiotocography were performed for low risk pregnancies. National Institute of Clinical Excellence (NICE), in its guidelines for cardiotocography monitoring, recommends intermittent monitoring for low risk labor and continuous cardiotocography monitoring for high risk labor [18].

Babies born with low Apgar, required resuscitation and some of them required ICU admission. In our study mostly Apgar score were more than 7 was $69(61.60 \%)$ cases and less than 7 Apgar score in 43 (38.39\%) in women undergoing cesarean section due to non-reassuring cardiotocography. However in the study ok Leung TY, reported 19 (10.9\%) required emergency intrapartum Cesarean delivery for non-reassuring fetal status and 15 (8.6\%) for poor progress. [19]

\section{Conclusion}

Cardiotocography is a useful and indispensable adjunct to monitor the condition of endangered fetus. However, there is a need to develop a standardized and unambiguous definition of FHR tracing to reduce the incidence of false positive findings that may result in increased incidence of unnecessary intervention particularly caesarean section.

\section{References}

[1] Khatun, A., Khanam, N.N. and Nazir, F. (2009) Role of Elaborate Cardiotocography 
in Pregnancy Management. Bangabandhu Sheikh Mujib Medical University Journal, 2, 18-24.

[2] Cesarelli, M., Romano, M., Bifulco, P., Fedele, F. and Bracale, M. (2007) An Algorithm for the Recovery of Fetal Heart Rate Series from Cardiotocography Data. Computers Biology and Medicine, 37, 663-669. https://doi.org/10.1016/j.compbiomed.2006.06.003

[3] Galazios, G., Tripsianis, G., Tsikouras, P., Koutlaki, N. and Liberis, V. (2010) Fetal Distress Evaluation Using and Analyzing the Variables of Antepartum Computerized Cardiotocography. Archives of Gynecology and Obstetrics, 281, 229-233. https://doi.org/10.1007/s00404-009-1119-8

[4] Sultana, J., Chowdhury, T.A., Begum, K. and Khan, M.H. (2009) Comparison of Normal and Abnormal Cardiotocography with Pregnancy Outcomes and Early Neonatal Outcomes. Mymensingh Medical Journal, 18, 103-107.

[5] Low, J.A., Killen, H. and Derrick, E.J. (2002) The Prediction and Prevention of Intrapartum Fetal Asphyxia in Pre-Term Pregnancies. American Journal of Obstetrics \& Gynecology, 186, 279-282. https://doi.org/10.1067/mob.2002.119642

[6] Malcus, P. (2004) Antenatal Fetal Surveillance. Current Opinion in Obstetrics and Gynaecology, 16, 123-128. https://doi.org/10.1097/00001703-200404000-00005

[7] Vintzileous, A.M., Nochimson, D.J. and Antsaklis, A. (1995) Comparison of Intrapartum Electronic Fetal Heart Rate Monitoring versus Intermittent Auscultation in Detecting Fetal Acidemia at Birth. American Journal of Obstetrics \& Gynecology, 173, 1021-1024. https://doi.org/10.1016/0002-9378(95)91320-3

[8] Chaillet, N., Dube, E. and Dugas, M. (2007) Identifying Barriers and Facilitators towards Implementing Guidelines to Reduce Caesarean Section Rates in Quebec. Bulletin of the World Health Organization, 85, 791-797. https://doi.org/10.2471/BLT.06.039289

[9] Shuchi, K., Rodgers, M.D., Cheryl, L., Kirby, M.D., Ryan, J., Smith, M.D., Mindy, M. and Horrow, M.D. (2012) Imaging after Cesarean Delivery: Acute and Chronic Complications. Radio Graphics, 32. http://pubs.rsna.org/toc/radiographics/32/6 http://dx.doi.org/10.1148/rg.326125516

[10] Geidam, A.D., Audu, B.M., Kawuwa, B.M. and Obed, J.Y. (2009) Rising Trend and Indications of Caesarean Section at the University of Maiduguri Teaching Hospital, Nigeria. Annals of African Medicine, 8, 127-132. https://doi.org/10.4103/1596-3519.56242

[11] Lohana, R.U., Khatri, M. and Hariharan, C. (2013) Correlation of Non Stress Test with Fetal Outcome in Term Pregnancy (37-42 Weeks). International Journal of Reproduction, Contraception, Obstetrics and Gynecology, 2, 639-645. https://doi.org/10.5455/2320-1770.ijrcog20131229

[12] Essen, B., Bodker, B., Sjoberg, N.O., Roos, J.L., Greisen, G., Gudmundsson, S., et al. (2002) Are Some Perinatal Deaths in Immigrant Groups Linked to Suboptimal Perinatal Care Services? An International Journal of Obstetrics \& Gynaecology, 109, 677-682. https://doi.org/10.1111/j.1471-0528.2002.01077.x

[13] Alfirevic, Z., Devane, D. and Gyte, G.M.L. (2006) Continuous Cardiotocography as a Form of Electronic Fetal Monitoring (EFM) for Fetal Assessment during Labour. Cochrane Database of Systematic Reviews, 3, CD006066. https://doi.org/10.1002/14651858.CD006066

[14] Oladrian, F.A. and Raphaeil, J.P. (2008) Abnormal Antepartum Cardiotocography and Major Fetal Abnormalities. Australian and New Zealand Journal of Obstetrics and Gynaecology, 28, 120-123.

[15] Kulkarni, A.A. and Shrotri, A.N. (1998) Admission Test: A Predictive Test for Fetal 
Distress in High Risk Labour. Journal of Obstetrics and Gynaecology Research, 24, 255-259.

[16] Chitra, R. and Neeru, T. (2001) The Role of Admission Test in Intrapartum Surveillance in: Abstract 44th ALCOG Conference, Ahmedabad.

[17] Elimian, A., Lawlor, P. and Figuerao, R. (2003) Intrapartum Assessment of FWB, Any Role of Fetal Admission Test? The Journal of Maternal-Fetal \& Neonatal Medicine, 13, 408-413. https://doi.org/10.1080/jmf.13.6.408.413

[18] Harvey, B. (2004) Use of Cardiotocography Monitoring, Are Recommendations Suitable? Royal College of Midwives, 7, 518-520.

[19] Leung, T.Y., Fok, W.Y., Chan, L.W., Law, L.W. and Lau, T.K. (2006) Prediction of Intrapartum Cesarean Delivery for Non-Reassuring Fetal Status after a Successful External Cephalic Version by a Low Pre-Version Pulsatility Index of the Fetal Middle Cerebral Artery. Ultrasound in Obstetrics \& Gynecology, 27, 416-419. https://doi.org/10.1002/uog.2700

Submit or recommend next manuscript to SCIRP and we will provide best service for you:

Accepting pre-submission inquiries through Email, Facebook, LinkedIn, Twitter, etc. A wide selection of journals (inclusive of 9 subjects, more than 200 journals)

Providing 24-hour high-quality service

User-friendly online submission system

Fair and swift peer-review system

Efficient typesetting and proofreading procedure

Display of the result of downloads and visits, as well as the number of cited articles

Maximum dissemination of your research work

Submit your manuscript at: http://papersubmission.scirp.org/

Or contact ojog@scirp.org 